\title{
URBANISMO E RELIGIOSIDADE NA IDADE MÉDIA
}

Eliana Ávila Silveira*

Abstract - This paper tries to establish a connection between the christianity and the development of urban society of Middle Ages. It analises the models of spirituality and the new forms of social behavior in the medieval cities.

O processo de ordenamento do mundo urbano nas formações sociais do Ocidente medieval no decorrer dos séculos XII e XIII promoveu profundas transformações nas estruturas materiais e mentais da sociedade européia. Tais transformações sugerem a possibilidade de se pensar a dinâmica histórica das relações entre urbanismo e religiosidade.' Afinal, o espaço urbano na Idade Média centralizou os principais equipamentos materiais e simbólicos do sagrado, erigiu um mundo de sentidos, que definia o sistema de moralidades religiosas e o comportamento social da coletividade cristã: a igreja, o convento mendicante, a confraria, o peditório, o albergue, o cemitério, a praça de pregação, a praça de condenação do Juízo de Deus, a praça da Redenção do Cristo Crucificado; enfim, o espaço urbano constituiu-se como paisagem e ambientação social fundamental para a proliferação

* Professora no Departamento de História da Pontifícia Universidade Católica do Rio Grande do Sul, Porto Alegre, RS, Brasil.

1 O presente artigo insere-se em um projeto mais amplo de investigação iniciado em 1997, que apresenta como marco fundamental de abordagem o estudo dos modelos de socializaçāo educativa na sociedade urbana da Baixa Idade Média hispânica. 
das manifestações coletivas da espiritualidade cristã. ${ }^{2}$ Em função dessa perspectiva analítica, partimos dos pressupostos de investigação assinalados por Dominique Julia no estudo dos movimentos religiosos. Segundo este enfoque de interpretação, deve-se considerar que: "A análise da articulação entre as espiritualidades, as devoções e os grupos considerados nas relações recíprocas que eles mantêm, uns com os outros onde elas se desenvolvem permite traçar sobre um espaço social uma geografia dos entrelaçamentos [...]." ${ }^{3}$ Portanto, a proposta central de investigação desse trabalho situa-se na interpretação das novas formas de expressão da religiosidade medieval que, em conexão com o universo social da cidade contribuíram decisivamente para inscrever e reforçar nos espaços urbanos emergentes um conjunto de instituições, comportamentos e valores espirituais destinados ao ajustamento das práticas cotidianas da piedade cristã. Trata-se de sublinhar duas questões importantes que marcaram a constituição dos movimentos religiosos e sociais da Cristandade Ocidental. Assim, primeiramente cabe explicitar os modelos de espiritualidade e de sensibilidade desenvolvidos no processo de evangelização e regeneração do comportamento social das coletividades urbanas. Em segundo demarcar os traços fundamentais que tipificaram os novos modelos de representação da religiosidade franciscana e dominicana nos procedimentos de pregação apostólica. Desse modo, as relações estabelecidas entre a espiritualidade mendicante com as cidades medievais apontam para o amplo significado que as manifestações do sagrado imprimiram à nova organização dos espaços sociais, físicos e mentais da sociedade. Como observa Jacques Le Goff, o movimento mendicante não escapou a uma relação estrita e dinâmica com as cidades medievais. Um dístico proverbial ilustrativo da espacialização física e espiritual

2 Os enfoques analíticos centrados no estudo das relaçôes entre religiâo e estrutura social apresentam uma pluralidade de correntes interpretativas. Da análise sociológica clássica conduzida por Max Weber, aos estudos antropológicos de Clifford Geertz, temos uma variedade de conceitos e aportes metodológicos voltados ao estudo das múltiplas dimensões que o fenômeno religioso comporta. Para uma síntese dessa problemática, ver: Hermann, Jacqueline. "História das religiōes e religiosidades". In: Cardoso, Ciro F. \& Vainfas, Ronaldo. Domínios da história: ensaios de teoria e metodologia. Rio de Janeiro: Campus, 1997, p. 329-352.

3 Julia Dominique. "Religião". In: LE GOFF, Jacques et al. A nova história. Coimbra: Almedina, 1990, p. 548. 
dos novos enquadramentos da cultura religiosa cristã pode ser observado na seguinte afirmação: Bernardo amava os vales, Bento as montanhas, Francisco as povoações, Domingos as cidades populosas. O autor ao enfatizar o movimento acelerado de implantação das novas ordens religiosas na cristandade, sublinha a importância do processo de estabelecimento dos conventos mendicantes na organização e caracterização da rede urbana da Idade Média. De acordo com Le Goff:

"As ordens parecem assim ter quadriculado todo o espaço urbano da cristandade, a tal ponto que o mapa dos conventos mendicantes se confunde com o mapa urbano e que o critério mendicante pode sugerir como melhor meio de referenciar a rede urbana numa época em que o vocabulário urbano é muito incerto e as definições da cidade muito vagas." ${ }^{4}$

Contudo, nesse trabalho não pretendemos estabelecer um estudo dos equipamentos materiais (arquitetônicos, artísticos e funcionais) presentes no mundo urbano e no delineamento espacial da religiosidade cristã..$^{5}$ Antes trata-se de privilegiar, especificamente, o estudo das configurações espirituais expressas nos novos modelos da religiosidade urbana desenvolvidos ao longo da sociedade medieval.

\section{Movimentos sócio-religiosos da cristandade}

Os séculos XII e XIII assinalam o crescimento de um processo significativo de clivagem espiritual e institucional na história do cristianismo Ocidental. As rupturas operadas no campo religioso, contudo, não estão dissociadas dos deslocamentos efetuados nas bases constitutivas da estrutura social senhorial característica da sociedade medieval. Contudo nas décadas iniciais do século XII, o crescimento urbano e o dinamismo das relações mercantis demarcam algumas alterações importantes na pluralidade dos comportamentos citadinos e na estruturação da vida social. Como observa Jacques Rossiaud: "A cidade é o centro do desenvolvimento de uma sociedade complexa,

4 Le Goff, Jacques. "As ordens mendicantes". In: BERLIOZ, Jacques. (org.) Monges e religiosos na Idade Média. Lisboa: Terramar, 1994, p. 227.

5 Ver: Duby, Georges (org). História artística da Europa. A Idade Média. São Paulo: Paz e Terra, 1997, p. 85. 
que se adapta ao sistema senhorial e à sua ideologia, mas que cria as suas próprias hierarquias [...] o que há de comum entre o mendigo e o burguês, entre o clérigo e a prostituta, todos citadinos." Sob esse aspecto, os diferentes tipos humanos circunscritos aos novos espaços urbanos, advindos em parte do processo de segmentação sócioprofissional em curso, delinearam formas distintas de convívio social e de práticas religiosas diversificadas na paisagem citadina. Um aspecto peculiar dos novos valores sócio-religiosos da cultura cristã nessa sociedade multifacetada foi o desenvolvimento do modelo de espiritualidade ativa. André Vauchez sublinha o caráter dinâmico do comportamento religioso do laicato no cenário social e cultural da vida urbana da Cristandade Ocidental. Conforme salienta o autor, a alteração das aspirações espirituais do mundo dos leigos apresentou um significado especial numa sociedade marcada pela expansão dos novos códigos de sociabilidade urbana. Assim, para Vauchez: "Essa aspiração difusa foi sentida mais vivamente nas cidades, onde o desenvolvimento do artesanato e do comércio criara um meio leigo dinâmico e combativo."

Tal comportamento contrastava com os elementos tradicionais norteadores das manifestações fundamentais da religiosidade medieval configurada, particularmente, no universo das relações sociais verticalizadas da sociedade senhorial. Assim, um rápido exame das principais tendências da espiritualidade cristã possibilita a compreensão das mudanças ocorridas na esfera das práticas religiosas perfiladas, sobretudo, no processo dinâmico de desenvolvimento da sociedade urbana.

O modelo de religiosidade do monaquismo ascético de tradição beneditina, mesmo em suas diferentes formas de renovação espiritual - cluniacense e cisterciense - estava fundamentalmente embasado na idéia de isolamento penitencial e de afastamento das realidades impuras do universo mundano. ${ }^{8}$ Portanto, o estado de purificação evangélica almejado nas instituições conventuais ao longo da Idade Média, deu lugar a um tipo de experiência espiritual ascética e de recolhi-

6 Rossiaud, Jacques. "O citadino e a vida na cidade". In: Le Goff, Jacques (org.) $O$ homem medieval. Lisboa: Editorial Presença, 1989, p. 61.

7 Vauchez, André. A espiritualidade na Idade Média Ocidental - séculos VIII a XIII. Rio de Janeiro: Zahar, 1995, p. 107.

8 Schmitt, Jean Claude. História de la superstición. Barcelona: Crítica, 1992, p. 17. 
mento frente aos males e tribulações da vida secular. O ideal monástico, cuja função religiosa específica insere-se num sistema de espiritualidade endógena foi marcado basicamente pela tentativa de superação permanente da condição terrestre. $O$ estilo de vida beneditino colocando-se como uma "escola do senhor" em oposição “à escola profana"," voltou-se para o desenvolvimento de posturas contemplativas e de interiorização dos valores espirituais. Como evidencia Jacques Berlioz: "Ilha de paz num mundo hostil, o mosteiro é um refúgio para quem deseja ter uma relação absoluta com Deus". ${ }^{10}$

A ênfase num modelo de religiosidade ascética, ritualizada e hierarquizada pelas normas estritas de comportamento espiritual da comunidade monástica (obediência, oração, trabalho e celibato) difundiu nos meios religiosos da cristandade atitudes de rejeição permanente ao conjunto dos valores temporais e carnais presentes na sociedade. Desse modo, o mosteiro, local por excelência de vivências espirituais de isolamento e penitência correspondeu historicamente ao amplo movimento de ordenamento social e religioso de um meio basicamente ruralizado e ligado às estruturas verticalizadas do sistema feudal $^{11}$. Nesse contexto, premissas doutrinárias importantes do sistema de valores predominantes na sociedade agrária e localista das primeiras fases da Idade Média, tiveram preferencialmente como marco referencial fundamental de vida espiritual o modelo do ascetismo conventual.

Entretanto ao longo dos séculos XII e XIII, a cidade passou a desempenhar um papel catalisador importante na vida social e espiritual da cristandade. Uma das características centrais da religiosidade desse período foi a formação do movimento de retomada do ideal de santificação pela via apostólica. A influência do modelo de vida apostólica concebida, então, como expressão plena da idéia do Cristo presente no mundo, possibilitou uma alternativa ao sistema de espiritualidade

9 JACQUES, Berlioz. Monges e religiosos na Idade Média. Lisboa: Terramar, 1994, p. 6.

10 Idem, p. 7.

11 Sobre os diferentes tipos de manifestações da religiosidade cristã no feudalismo, cabe registrar a espiritualidade belicista e penitencial das Cruzadas. Tal espiritualidade voltada ao mundo perfilou o cristianismo de guerra santa, que acabou incorporando uma ampla participação dos distintos segmentos da nobreza baronial e das massas populares. Ver, a respeito, Rousset, P. História das Cruzadas. Rio de Janeiro: Civilização Brasileira, 1981. 
reclusa dominante nos meios monásticos. O ideal apostólico consistia basicamente num programa de purificação mais abrangente e sistemático. Ele visava a renovação de um quadro normativo de vida perfilado na imitação das obras de Cristo e dos apóstolos e, assim, implicava no estabelecimento de um gênero de vida modelado nos primeiros santos da tradição cristã. Nesse sentido, assistiu-se a um movimento crescente de revitalização dos princípios evangélicos, que contribuiu consideravelmente para o reordenamento do sistema de valores espirituais da cristandade. Tal perspectiva evidenciava a idéia, muito difundida especialmente nas coletividades urbanas, de uma necessidade imperiosa de renovação da religiosidade, um desejo de vivência profunda dos valores espirituais praticados e difundidos pelos apóstolos na Igreja Primitiva. ${ }^{12} \mathrm{O}$ esforço empreendido pelas comunidades leigas incidiu, sobretudo, na constituição de movimentos espirituais destinados a revigorar e afirmar os pressupostos da ordem divina na totalidade do corpo social. Um dos procedimentos mais destacados do novo movimento de purificação da religiosidade na sociedade medieval foi a difusão dos preceitos cristãos em suas formas de expressão radicalmente evangélicas. Essas aspiraçōes faziam parte de uma tendência geral que, de um lado, incorporava as manifestações religiosas das comunidades leigas marcadas fortemente pelo sentimento de revivalismo evangélico e, de outro, compreendia também o propósito dos setores reformistas do clero empenhados na moralização das instituições eclesiásticas. Todavia, o novo fenômeno religioso exerceu uma influência significativa na propagação de crises e dissensões no interior do sistema de crenças da espiritualidade cristã.

Os principais problemas delineados na crise espiritual da sociedade medieval dos séculos XI e XII, concentravam-se em torno de algumas questões fundamentais, especialmente as de natureza institucional e doutrinária. De qualquer forma, tais problemas não estavam dissociados de solicitações mais exigentes nos domínios da moralidade religiosa. Nessa perspectiva, floresceram na cristandade focos exacerbados de tensões espirituais e de conflitos sociais sobre os mais diferentes problemas que afligiam a vida interior e ameaçavam as práticas religiosas do mundo leigo e eclesiástico. Dentre os problemas marcantes na esfera das concepçôes religiosas do período podem ser

12 Duby, Georges (org.). História artística da Europa. A Idade Média. São Paulo: Paz e Terra, 1997, p. 88. 
situados basicamente os seguintes: as relações conflitivas entre o poder espiritual e o temporal, o problema da ritualização excessiva das práticas litúrgicas conventuais, as críticas constantes ao enriquecimento material das instituições eclesiásticas e o afastamento do clero secular das atividades do proselitismo pastoral.

Desse modo, o movimento espiritual de restauração dos princípios apostólicos do cristianismo no decorrer dos séculos XI e XII, produziu no seio da cristandade a proliferação de movimentos religiosos marcados por concepções doutrinárias e por formas organizativas espirituais diferenciadas. De maneira geral, esses movimentos estavam ligados a um processo de individualização crescente da experiência religiosa que conferia um papel novo e peculiar ao desenvolvimento da consciência espiritual. Tais fenômenos da religiosidade evidenciavam o desejo de participação ativa e direta do laicato nas manifestações de piedade. Alguns, contudo, tomavam formas convencionais e pessoais de ascetismo eremítico. Nessa perspectiva, os seus adeptos buscavam na exclusão voluntária da vida social o isolamento propício a uma existência penitencial de aprimoramento espiritual. Outros, porém, proclamavam a necessidade de criação de novas ordens religiosas destinadas ao aperfeiçoamento da disciplina eclesiástica. Assim, no decorrer século XI, ocorreu a emergência da concepção gregoriana de renovação da vida apostólica que estimulou o trabalho dos religiosos para a tarefa de difusão evangélica. Tal é o caso da criação nesse período da ordem dos cônegos agostinianos, sob a influência das idéias reformistas do papa Gregório VII.

Por outro lado, esse período de intensa ebulição da vida religiosa medieval provocou o impulso extraordinário dos movimentos evangélicos no interior das próprias comunidades urbanas. Nesse sentido, o movimento espiritual promoveu o desenvolvimento de novas formas de religiosidade dissociadas das estruturas institucionais da igreja. A cidade de Milão por exemplo, em 1175, foi marcada pelo aparecimento de comunidades espirituais de leigos ("Humilhados"), preocupados em vivenciar experiências evangélicas integrais. De maneira geral, essas comunidades eram formadas por grupos de trabalhadores urbanos dos ofícios têxteis. Essas comunidades estavam empenhadas em conjugar as tarefas cotidianas do trabalho, com uma vida religiosa regrada por orações, penitências e obras de caridade. Em 1184, os grupos evangélicos foram excomungados pela ação disciplinadora do 
poder eclesiástico. Muitos integrantes dos Humilhados já desenvolviam um intenso trabalho de proselitismo pastoral nas cidades da Lombardia, e assim, acabaram por entrar em conflito com as autoridades clericais locais. Todavia, foram posteriormente reintegrados à Igreja, pela iniciativa do papa Inocêncio III.

Entretanto, o florescimento espiritual do período foi também acompanhado pelo desenvolvimento de formas de entendimento religioso distintas da ortodoxia doutrinária defendida pelo sistema hierárquico sacerdotal da Cúria Romana.

Nessa perspectiva, a expansão do evangelismo popular no tecido social da cristandade contribuiu para provocar o aparecimento de fortes tensões religiosas e o desenvolvimento de conflitos sociais acirrados nas relações entre leigos e cléricos. O resultado imediato dessas tensões sócio-religiosas foi o recrudescimento dos movimentos heréticos em toda a cristandade. ${ }^{13}$ Em função disso, pode-se conceber as heresias medievais como sistemas sócio-religiosos de oposição, nem sempre integrados ou coesos, mas representativos de "ideologias de contestação". ${ }^{14}$ De maneira geral, os movimentos heréticos medievais (valdense, cátaro ou albigense, por exemplo) se mostravam em muitos aspectos refratários ou em oposição frontal aos pressupostos religiosos e modos de vida definidos pelo sistema de poder da hierarquia eclesiástica. A heresia cátara, por exemplo, configurou um movimento de reação constante aos fundamentos da ortodoxia cristã. O catarismo apresentou um processo de crescimento considerável no decorrer dos séculos XII e XIII, atingindo vastas áreas dos territórios da cristandade. Contudo, o movimento herético foi particularmente intenso nas cidades e nos povoados da Itália, França e Suiça. O catarismo plasmou concepções e práticas religiosas extremamente diferenciadas dos dogmas da ortodoxia da Igreja papal. O movimento renegava totalmente o Antigo Testamento, desconsiderava a instituição sacramental, o ritualismo do culto cristão ortodoxo e a proliferação de igrejas e templos suntuosos. Os integrantes da seita formavam comunidades autônomas perfiladas em concepções maniqueístas e de acentuado purismo espiritual. Nesse contexto, o controle sistemático da Igreja sobre as comunidades dissidentes atingidas pela influência dos movimentos heterodoxos levou, por fim, ao emprego da Inquisição (Con-

13 Falbel, Nachman. Heresias medievais. São Paulo: Perspectiva, 1977, p. 60.

14 Idem, p. 62. 
cílio de Toulouse - 1229) e à formação de cruzadas especiais como instrumentos complementares de repressão aos grupos heréticos. ${ }^{15}$

Desse modo, na perspectiva de regresso aos princípios básicos da religiosidade dos tempos da comunidade apostólica primitiva, o revivalismo evangélico acabou promovendo o deslocamento das formas tradicionais da espiritualidade cristã. No entanto, como veremos a seguir, as novas práticas do evangelismo revigorado também possibilitaram o desenvolvimento de comunidades religiosas, cujas estruturas de organização foram canalizadas e incorporadas aos fundamentos institucionais da ortodoxia eclesiástica.

\section{Igreja e pobreza na sociedade urbana}

As Ordens Mendicantes surgidas no contexto das transformações religiosas da sociedade medieval, configuradas a partir das inquietações espirituais de São Domingos de Gusmão (1170-1221) e de São Francisco de Assis (1181-1226), demarcaram na história do cristianismo ocidental um novo encontro da Igreja com a pobreza social urbana. Evidentemente, o processo de crescimento das cidades da Cristandade, quando associado ao novo fenômeno social e religioso do apostolado mendicante, não pode ser descrito como o resultado de uma evolução histórica linear das estruturas materiais e mentais da sociedade medieval. Cabe considerar, no entanto, os elementos de conexão estabelecidos entre as formas de espiritualidade apresentadas pelas novas ordens religiosas e os movimentos dinâmicos da estrutura social. Uma série de estudos de Michel Mollat sobre a história social da Idade Média sublinha o significado relevante dessa problemática de investigação no campo de análise dos movimentos religiosos da cristandade ocidental. Tratando-se das relações entre a religiosidade desenvolvida no meio urbano e a formação das ordens mendicantes, Mollat, por exemplo, adverte para alguns aspectos importantes da natureza social desses movimentos. Para o autor, portanto:

"[...] um dos aspectos significativos e novos foi a correspondência entre o princípio da fraternidade, essencial às Ordens Mendicantes, e as solidariedades horizontais do meio urbano, adotadas particularmente entre os pobres. Ao esquema vertical e hierárqui-

15 BOLTON, Brenda. A Reforma na Idade Média. Lisboa: Ediçôes 70, 1986, p. 31. 
co, tradicional, da pregação do prelado que desce até suas ovelhas, substitui-se pelo contágio exemplar da reciprocidade da partilha caridosa da pobreza."16

Nessa perspectiva, deve-se destacar os traços gerais das estruturas políticas e sociais das cidades medievais que, em grande medida, caracterizavam-se pelo poder do novo patriciado urbano dos comerciantes ou, de outra parte, apresentavam o sistema de autoridade tradicional mantido pelas elites senhoriais. Assim, o quadro social de solidariedades horizontais emergente no mundo urbano, congregando, sobretudo, os conselhos municipais, as guildas e os diferentes tipos de associaçóes de ofícios, na maioria das vezes excluía os habitantes pobres, os imigrantes e, em muitos casos, os próprios segmentos médios das populaçōes citadinas. Como assinala Rossiaud:

"[...] beneficiar dessa solidariedade coletiva pressuponha uma cidadania difícil de conquistar; implicava uma admissão, a existência de um padrinho, um período de residência muitas vezes superior a um ano, a inclusão num ofício ou a aquisição de um imóvel. Fazer parte do povo não era fácil e uma maioria de habitantes desprovidos de recursos revelava-se incapaz de transpor as muralhas erguidas no interior de uma minoria ociosa". ${ }^{17}$

Procurando conter e ordenar os desajustes políticos e sociais produzidos pelas novas circunstâncias históricas do momento, os frades mendicantes buscaram criar um novo cenário público pautado num sistema ideal de solidariedades cristãs. Com efeito, o conjunto de condutas religiosas desenvolvidas pelos mendicantes na nova sociedade urbana acabaram por reorientar os procedimentos tradicionais de ação da Igreja medieval sobre o conjunto dos fiéis. Assim, tendo em conta uma percepção direta das novas circunstâncias sociais geradas pelo crescimento desordenado das cidades da cristandade, as novas ordens realizaram um trabalho pastoral distinto, que ultrapassava, em grande medida, o campo de ação dos especialistas tradicionais da fé: o religioso secular, o padre e o monge. De acordo com Mollat, os mendicantes partiram da formulação de considerações peculiares e dinâmicas sobre o significado da pastoral na nova paisagem social:

\footnotetext{
16 Mollat, Michel. Os pobres na Idade Média. Rio de Janeiro. Campus, 1989, p. 181.

17 ROSSIAUD, op. cit, p. 101.
} 
"Não fugiram das cidades, onde o progresso da economia de troca desenvolvia a atração pelo dinheiro. Francisco recusou as regras anteriores da vida monástica que a Cúria lhe propunha a fim de não se isolar, como os monges ou brancos e os Cartuxos. Domingos, embora conservasse o quadro canonical, deu-lhe o estilo de uma pastoral direta e flexível, metodicamente aberta aos problemas do momento."18

Assim, os mecanismos de atuação e a amplitude do campo de abrangência das novas ordens na religiosidade cristã contribuíram para conferir uma mudança significativa nos procedimentos da comunicação mística, tanto em suas formas exteriores de manifestação, quanto pelo conteúdo das mensagens evangélicas transmitidas ao novo público citatino. Nessa perspectiva, uma das funções mais importantes da nova pastoral dos frades mendicantes foi decorrente da necessidade de moralizar o comportamento das populações citadinas, dar sentido a uma pedagogia simplificada das virtudes cristãs e, fundamentalmente, despertar o valor da consciência caritativa no meio social e econômico produzido pelas novas estruturas emergentes.

Os traços que definiram o novo modelo de espiritualidade dos mendicantes no século XIII, traduziram basicamente a ênfase num conjunto de concepções e práticas religiosas abertas ao mundo. As novas ordens religiosas almejaram revitalizar os propósitos de uma espiritualidade cristocêntrica expressa nos ideais de restauração da vida apostólica. A vida de Cristo e dos apóstolos revela-se como um dos pontos de centralidade de uma espiritualidade purificadora e humanizante, que rompendo com o isolamento da vida religiosa do claustro voltou-se para um projeto de evangelização abrangente destinado a espiritualização de todo o corpo social. Assim, atuando de forma distinta e rompendo com o isolamento espiritual do monasticismo tradicional, que situava a instância superior da religiosidade cristã na vivência do claustro, os irmãos pregadores dirigiram o seu olhar aos homens e à obra divina da criação presente no universo.

Desse empreendimento apostólico um dos grandes artesãos foi Francisco de Assis, que inaugurou o naturalismo religioso e uma nova sensibilidade espiritual na história do cristianismo. Na pregação franciscana tratava-se, antes de tudo, de uma retomada visceral dos princípios apostólicos da plenitude da fé, como expressão da sensibilidade 
amorosa ao outro. No campo da espiritualidade mendicante do século XIII, como assinala Georges Duby, "a fé torna-se uma questão amorosa, uma questão de relações afetivas". ${ }^{19}$ Francisco, oriundo de uma família de ricos mercadores italianos da região da Úmbria, exerceu o apostolado do despojamento material e espiritual, notabilizando-se por sua identificação com o mundo dos deserdados, os "MINORES" da estrutura social. Em 1223, a nova comunidade dos irmãos menores foi reconhecida oficialmente pela Igreja. Aos dirigentes do clero, notadamente para Inocêncio III (1198-1216) e Gregório IX (1227-1241), os frades menores indicavam a possibilidade de recondução do laicato aos caminhos da ortodoxia católica.

Nessa altura, o trabalho pastoral da comunidade de Assis já havia adquirido um significado especial nas relações entre os novos religiosos e os elementos da sensibilidade espiritual das populações citadinas. A difusão do movimento de renovação apostólica baseado em concepções e atitudes pias de benemerência social voltava-se, sobretudo, para o rompimento dos elos de uma cadeia de indiferença moral e social, que o crescimento da economia urbana havia produzido na vida social das cidades da cristandade. Nessa perspectiva, os mendicantes representaram a face revigorada do movimento de expansão das comunidades evangélicas populares da sociedade medieval. Portanto, a nova sociedade urbana foi um terreno de extrema fecundidade para a proliferação dos movimentos populares de pregação apostólica. A revigoração dos princípios evangélicos no tecido social urbano adquiriu um sentido religioso vital num contexto de incertezas e angústias coletivas.

Por outro lado, a nova comunidade dos Irmãos Pregadores, constituída por Domingos de Gusmão, em 1215, ordenou-se junto a um amplo programa evangélico dedicado ao trabalho de conversão dos heréticos. Contudo, a nova ordem religiosa não deixou de estar ligada às preocupações centrais geradas pelo ideal de mendicidade. Em 1205-1260, Domingos, originário de Calaruega, localidade de Espanha, fervoroso adepto da espiritualidade apostólica, empreendeu os primeiros esforços num programa intenso de conversão das populações marcadas pelo catarismo. Domingos multiplicou o movimento de ação apostólica atuando especialmente no trabalho de conversāo das comunidades heréticas do Languedoc e da Provença.

19 Duby, op. cit., p. 108. 
A ordem dominicana mostrou-se particularmente sensível aos novos espaços urbanos. De maneira geral, os pregadores dominicanos associaram o conceito de urbanidade ao universo das práticas heréticas. Nesse sentido, já nos primórdios da comunidade religiosa, Domingos estabeleceu algumas premissas importantes para a eficácia da pregação apostólica. A nova ordem estimulou a preparação intelectual dos noviços, enfatizou com rigor os estudos teológicos e o conhecimento dos métodos de exposição racional das Escrituras, como meios indispensáveis à eficácia da pregação evangélica. A conseqüência dessas orientações diretivas foi o desenvolvimento de uma ordem de intelectuais - uma ordem de doutores -, dentre os quais destacaram-se no cenário público das universidades medievais as figuras de Alberto Magno e de São Tomas de Aquino. Assim, a presença dos dominicanos nas estruturas de ensino das universidades européias contribuiu decisivamente para alargar os horizontes da atuação intelectual e religiosa da ordem nas novas instituiçốes culturais da sociedade medieval. Por outro lado, os dominicanos esforçaram-se, sobretudo, por promover a dimensão intelectual do ofício da pregação. Já os franciscanos operaram fundamentalmente na dimensão da sensibilidade religiosa, como exercício de aproximação afetuosa entre o religioso e o fiel. Porém, nas novas ordens, as formas e os temas da pregação foram ao longo do tempo, sendo pautados sobre esses duplos fundamentos, empregados um após o outro, mas sempre orientados como funções complementares.

O dominicano Vicente Ferrer, um dos pregadores populares mais consagrados da Espanha do século XIV, estabeleceu em seu Tratado de la vida espiritual alguns procedimentos essenciais nos domínios da oratória sacra. Uma das principais funções dessa espiritualidade apostólica foi o empenho na pregação itinerante, que levou Vicente Ferrer, originário da cidade de Valência, aos mais distantes povoados e centros urbanos da cristandade medieval: Barcelona, Lérida, Murcia, Madri, Toledo, Sevilha, Toulouse, Avignon, Paris, Milão, Roma e Nápoles. Os seus sermões, que atraíam contingentes consideráveis das populações citadinas da cristandade, estendiam-se por longos períodos de pregação realizados em púlpitos construídos especialmente nos passeios e praças públicas das principais cidades européias. A escolha dos temas e dos locais de pregação eram manifestações de uma vontade evidente de moralizar as práticas cristãs, de levar os fiéis ao exercício das virtudes evangélicas da caridade e, do desejo de persuadir ao 
abandono dos pecados mais comuns no meio urbano: a avareza, a usura, a luxúria, o falso testemunho e os comportamentos cismáticos. No entanto, a pregação evangélica deveria corresponder aos anseios do público ouvinte e, assim, Ferrer assinalou em seus escritos, destinados basicamente aos próprios religiosos da ordem, alguns preceitos fundamentais do movimento pastoral. Aos religiosos recomendava:

"En todos los semones que en público tuvieres y en las pláticas y exhortaciones particulares, usa siempre de lenguaje sencillo, llano y casero, para dar a entender las obras particulares de cada uno, descendiendo a los actos singulares [...]. Mas esto de tal modo has de hacer que eche de ver salen tus palavras de pecho no soberbio [...] sino de entranãs llenas de caridad y amor paternal."20

Comover e convencer, constituíram-se nos elementos fundamentais da comunicação sacra desenvolvida pelas novas ordens mendicantes na paisagem urbana. O seu destino: a praça pública, o sermão popular, a universidade, os estudantes e os núcleos de populações de todos os locais da cristandade e, portanto, o novo apostolado urbano. O resultado dessas novas atitudes religiosas foi o desenvolvimento de uma categoria de intelectuais expressivos e, de outra parte, de pregadores populares identificados com o seu público, capazes de restaurar a autoridade e a moralidade espiritual, a ordem e o equilíbrio social de um cenário humano em mutação.

\section{Consideraçôes finais}

Como foi notado no decorrer deste trabalho, uma característica particularmente importante do urbanismo medieval resulta de sua relação estreita com os movimentos de renovação da religiosidade cristã. Ao lado da diversidade funcional que a nova rede urbana da cristandade apresentou no âmbito das relações econômicas e sociais, os espaços citadinos constituíram-se como locais privilegiados para um conjunto de manifestações pias e caritativas da espiritualidade, com vistas ao atendimento dos segmentos populares. Nesse sentido, os diferentes modelos de vida religiosa dos séculos XII e XIII assinalaram mutações e clivagens significativas na esfera das práticas devo-

20 Garganta, José Maria \& Forcada, Vicente. Biografia y escritos de San Vicente Ferrer. Madrid: Biblioteca de Autores Cristianos, 1956, p. 513. 
cionais. Assim, em conseqüência de um acentuado fervor religioso nos ideais cristocêntricos da fé apostólica renovada, as populações urbanas desenvolveram formas mais ativas de participação nas manifestações de piedade. Por outro lado, as idéias de benemerência social difundidas pelas novas ordens mendicantes serviram de base para a afirmação dos modelos evangélicos sem contudo, provocar a dissociação entre o núcleo primitivo das devoçôes cristãs e o aparelho institucional da igreja. Nesse sentido, as ordens dos irmãos pregadores promoveram a difusão de um processo de evangelização voltado ao encaminhamento religioso das populações citadinas, porém, tendo em vista fundamentalmente os padrões de moralidade espiritual e de coesão da ordem social. Portanto, os mendicantes realizaram uma tarefa complexa na esfera das práticas e das crenças espirituais cristãs, especialmente ao tentarem unir e dar coesão aos segmentos da alta cultura religiosa formulada pela hierarquia eclesiástica, com os movimentos evangélicos produzidos na base da estrutura sócio-religiosa da cristandade Ocidental.

\section{REFERÊNCIAS BIBLIOGRÁFICAS}

BAKHTIN, Mikhail. A cultura popular na Idade Média e no Renascimento. O contexto de François Rabelais. São Paulo: HUCITEC, 1993.

BERLIOZ, Jacques (org.). Monges e religiosos na Idade Média. Lisboa: Terramar, 1996.

BOLTON, Brenda. A Reforma na Idade Média. Lisboa: Ediçôes 70, 1986.

BURKE, Peter (org.). A escrita da história - novas perspectivas. São Paulo: UNESP, 1992.

CARDOSO, C. Flamarion e VAINFAS, Ronaldo. (orgs.). Domínios da história: ensaios de teoria e metodologia. Rio de Janeiro: Campus, 1997.

DUBY, Georges (org.). História artística da Europa - Idade Média. Rio de Janeiro: Paz e Terra, 1997.

— Senhores e camponeses. Sāo Paulo: Martins Fontes, 1990.

—. As três Ordens ou o imaginário do feudalismo. Lisboa: Estampa, 1982.

ELIADE, Mircea. Tratado de história das religiões. São Paulo: Martins Fontes, 1993.

FALBEL, Nachman. Heresias medievais. Sāo Paulo: Perspectiva, 1977.

GARGANTA, José Maria \& FORCADA, Vicente. Biografia y escritos de San Vicente Ferrer. Madrid: Biblioteca de Autores Cristianos, 1956.

GINZBURG, Carlo. Mitos, emblemas, sinais: morfologia e história. São Paulo: Companhia das Letras, 1991.

O queijo e os vermes: o cotidiano e as idéias de um moleiro perseguido pela inquisição. São Paulo: Companhia das Letras, 1989. 
LE GOFF, Jacques. A nova história. Coimbra: Almedina, 1990.

. O apogeu da cidade medieval. São Paulo: Martins Fontes, 1992.

. O homem medieval. Lisboa: Editorial Presença, 1989.

. Os intelectuais na Idade Média. Lisboa: Gradiva, 1984.

LOPEZ. Robert. A cidade medieval. Lisboa: Editorial Presença, 1988.

. A Revolução Comercial da Idade Média 950-1350. Lisboa: Editorial Presença, 1986.

MOLLAT, Michel. Os pobres na Idade Média. Rio de Janeiro: Campus, 1989.

MULLET, Michael. La cultura popular em la baja Edad Média. Barcelona: Crítica, 1990.

SCHMITT, Jean-Claude. História de la superstición. Barcelona: Crítica, 1992.

VAUCHEZ, André. A espiritualidade na Idade Média ocidental séculos VIII a XIII.

Rio de Janeiro: Zahar, 1995. 